\title{
Human Rights and the Medical Care Narrative
}

\author{
Neeraja Sundaram \\ Assistant Professor, School of Liberal Studies, Azim Premji University, Bangalore, India. \\ Email: neeraja.s@apu.edu.in
}

\begin{abstract}
This paper aims to find convergences in the field of Human Rights and Literature and the literary study of illness narratives. Both these fields of study focus on the emergence of a new kind of subject via the telling of stories that organize experiences of traumatic suffering. The central focus in Human Rights and Literary studies continues to be on the narration of atrocities ranging from genocide, torture and imprisonment to the condition of people inhabiting conflict zones. Literary studies of the medical memoir, a sub-genre of the autobiography, is similarly interested in the discursive processes and strategies through which individuals come to terms with experiencing and witnessing physical decline, death and impairment because of illness. I hope to show in this paper that narratives of illness can be productively situated within a Human Rights framework and will thus allow us to see these narratives as performing a crucial role in the social imaginary of rights and ethics in the context of medical care.
\end{abstract}

Keywords: medical memoir, Human Rights, narratives of illness, medical care

Slaughter (2009) for instance, has argued that cultural representations (self-representations like the memoir and testimonio) have the potential to repress as well as resist in the social imaginary, making visible to the world, the voices of the oppressed and social conditions of oppression in radically new vocabularies and modes of writing. Illness narratives, this paper will argue, when situated within this formulation of being a cultural representation that seeks to engage the social imaginary that organizes illness experience and medical care, can be seen to activate a discourse of human rights.

Illness narratives within literary studies encapsulate a range of forms from the more traditional memoir or self-representation of an event of illness and its medical management to the more recent form of graphic narratives and even selfies of ill-health. In this paper I will focus on a specific articulation of the illness experience: caregivers' accounts of witnessing illness and providing medical care. I will study here, stories narrated by individuals caring for those suffering from mental illness and cognitive decline in India. The texts I will focus on here include Jerry Pinto's Em and the Big Hoom (2012) and Amandeep Sandhu's Sepia Leaves (2007). Each of these texts are accounts by primary caregivers of the mentally ill and are representative of what Smith and Shaffer (2004) title "meta-sites for social critique" in the context of personal narratives of human rights. I will argue here that a cultural domain of illness experience is articulated in these narratives through a specific language of rights which in turn emerges as a new discourse for rights. The "cultural domain" will here signify a) the specific filial or para-institutional contexts for illness experience b) a regionally, ethnically and historically specific location for these stories. For instance, Pinto's Em and Sepia Leaves both also provide a lot of deep context for life in Goan

(C) AesthetixMS 2019. This Open Access article is published under a Creative Commons Attribution Non-Commercial 4.0 International License (http://creativecommons.org/licenses/by-nc/4.o/), which permits non-commercial re-use, distribution, and reproduction in any medium, provided the original work is properly cited. For citation use the DOI. For commercial re-use, please contact editor@rupkatha.com. 
Christian communities and Sikh communities respectively while also locating them in specific points in India's history - Sepia Leaves is set during the Emergency and Em oscillates between late 2oth c Bombay and the Bombay of Pinto's parents' generation c) an appeal for rights to health and medical care that takes into account culturally specific contexts while also recognizing the erosion of subjectivity posed by the onset on certain illnesses. For example, these narratives testify to the diversity inherent in the experience of mental disorders as well as detailing various psycho-social stressors that are seen to be endemic to modes of social organization in India like the heteronormative, patriarchal family unit.

Before moving on to exploring the discourse of rights articulated by the caregiver's account of illness, I will briefly provide an overview of intersections between scholarship on the literary study of Human Rights and that of health and medicine.

\section{Human Rights, Narrative and Illness}

James Dawes has argued for the foundational role played by stories and storytelling in Human Rights work (2009). Building on Lynn Hunt's much cited work, Inventing Human Rights, Dawes signals to the evolution of narrative practices (Lynn Hunt has argued for the role played by the epistolary novel in the eighteenth century in England in crystallizing Enlightenment ideals about the Human) in the modern period that include literary forms like the testimonio which co-exist alongside legal initiatives like South Africa's Truth and Reconciliation Commission. The testimonio, along with the TRC is here part of a socio-cultural apparatus of narration and healing where stories assuming a particular structure and location can work to redress and recode trauma and atrocity. Dawes also draws attention to something that continues to be at the center of debate in Human Rights scholarship as well as literary studies of medicine, illness and health: the ethics of narration. The narrative organization of an illness experience and its medical management has been studied for the way it impacts our cultural notions of states of being like "healthy", "sick" or "disabled" as well as for its reparative potential for narrators and listeners/readers ${ }^{\mathrm{i}}$. In addition, literary studies of the medical memoir have also meditated on the ethics of narration - Who has the right to narrate in the event of illness? How is the narrating subject impacted in the event of illness? Do stories about illness and healing organize our modes of thinking about and responding to those who are ailing? This paper aims to extend current arguments about the ethics and impact of narrating stories about illness from a little-explored perspective within the genre of the medical memoir - the caregiver. Em and the Big Hoom as well as Sepia Leaves evoke several questions about the ethics of narration just by their chosen form: fiction. Both Pinto and Sandhu interestingly record the basis of their works in "truth" in paratexts and online forums rather than situate Em and the Big Hoom or Sepia Leaves as memoir or autobiography. Both books are marketed under the category of novels in India, while reviews and interviews with authors (in the case of Sepia Leaves, the author's blog carries an epilogue to the novel that describes his mother's death as well as a confession about the extent of "truth" in the events described) insist upon and explore the basis of these narratives in real-life experiences and incidents. Both authors have also repeatedly testified to their own discomfort and difficulty in narrating their experiences in a "public" and material (marketable) form. This careful staging of the stories' content and who has the "right" to testify to their truth reveals an interesting tension between the reparative potential of narrative and the ethics of how, to who and in what manner this potential is harnessed. While the question of contexts of production, consumption and circulation of illness narratives will not be explicitly explored here, the tenuous claims of these 
texts to the category of "fiction" make them suitable for study as articulating a Human Rights discourse in the context of illness and its medical management.

Human Rights and Literature in the context of India have been studied as an instance of dual translation where local contexts of rights abuse and suffering enter a global arena of Human Rights debates thus acquiring visibility but also simultaneously become informed by universal standards of evaluating and defining Human Rights (Nayar, 2011). The cultural apparatus of Human Rights for Nayar is thus not only a "cultural imaginary" of rights and ideas of the Human but also a translation of international Human Rights norms into local contexts and reading/interpreting local stories/narratives in global, universal terms. Nayar has also argued elsewhere for locating diverse narratives of suffering along a continuum, where there exists a possibility for reading/interpreting "rights denied through various modes" together rather than creating a hierarchy of victims (xvi, 2016). In other words, while stories of suffering may not be identical, violations of the Human and the denial of rights can be seen in Nayar's words as "equivalent if not equal" (xvi). In this paper I want to situate the medical memoir in India as articulating a claim "equivalent" to those studied in existing HR and literature scholarship, albeit in the context of illness, specifically caregiving, and as attempting to read local and individual suffering, abuse and neglect using global contexts/frames for understanding the Human. For instance, Jerry Pinto describes the inmates he sees during a college trip to the Thane mental hospital thus:

They all looked alike in dirty grey white clothes and near-shaved heads. They looked dehumanized, as if their identities had been stolen. They looked like something from a Holocaust film. (195)

Pinto's account of this scene at the mental hospital is interesting for the range of global and local contexts that are invoked together for the reader. While the scene is situated in Thane, Mumbai, the patients are explicitly located as those that have been divested of their "human" status - here he appeals to a universal rather than a more regional or national category/identity. In addition, Pinto compares how the patients look to a situation that is very far removed for the average Indian reader or even the patients themselves: the Holocaust. The Holocaust is invoked here as a representational category (Holocaust film) rather than the event itself, thus likening the stories that circulate about human suffering, deprivation and degradation to a fabula of sorts, a metaframework that permits one to visualize many different forms of suffering through a shared lens.

I will end this section on the productive intersections between the study of illness and Human Rights within literary studies with a reflection on the subset of the medical memoir this paper deals with: the caregiver's tale. Ann Burack-Weiss, in her study of caregiving memoirs also interestingly evokes parallels with memoirs that detail suffering, not necessarily in the context of illness. Writing about her methodology in reading and researching memoirs by caregivers she says, "I began to think of memoirs of slavery, the Holocaust, the Depression. A microcosm of the event could be seen in each story, while each story illuminated the whole" (xvi). She too argues for the caregiver's account as demonstrating equivalences with other narratives of suffering, though activated by a diversity of social, political and historical factors. In addition, she identifies in the caregiver's tale several formal features that unite stories across various situations (illness and disability), relationships (largely written by carers in the family) and form (the memoir). Most significantly for the discourse of rights examined here, Burack-Weiss identifies what she calls the "fable" of the caregiver's experience which for the researcher, functions as the "collective truth" about providing care for someone who is ailing. This collective truth is not necessarily a quest for "what really happened", but rather, is a mode of how experiences are made sense of, organized 
and shared by writers and readers who are embedded in care situations. The caregiver's tale thus organizes our experiences and modes of understanding what care is and what it entails.

Caregiving accounts have also been studied for their capacity to be "relating narratives" that take on the ethical task of chronicling and bearing witness to aspects/events during illness that are inaccessible to the patient herself (Whitehead, 2011). In our desire to tell others who we are, we often rely on the stories of others to narrate our "self". In addition, the "humane" treatment of the patient, whose individualized experience of illness is threatened in the face of a universalized medical diagnosis and treatment, relies on the reconstruction of the patient's "prior self" by the caregiver (Rowe, 2002). The contexts of caregiving studied here further complicate the dynamics of the carer and cared for, especially in the context of chronic illness and end-of-life care, since this is not only a role taken up briefly but is often part of the day-to-day of family life. Caregiving in the context of mental illness, in the case of the texts studied here, is seen to be already part of narrators' family contexts and experiences and is something they have learned to engage with from their youth until late adulthood. Caregiving in the context of mental illness is also unusual in terms of how it challenges "filial" ties: sons and daughters are often providing care in contexts where mentally ill parents no longer recognize themselves or their children as belonging to a family. Care here thus also extends to and redefines contexts that are undermined by altered and altering subjectivities in the face of illness. The caregiver's narrative is thus also a testimony of how filial ties were sustained through acts of care during illness rather than an account of how illness alone necessitated care. The caregiver narrative can also be situated within an emerging genre of the medical memoir that Harris et al describe as being about "emerging states of illness liminality" (64). They describe the authors of these texts as "patients-in-waiting" who nevertheless conform to as well as rewrite some of the formal properties of illness narratives. Harris et al are studying the "autobiological" digital narratives of YouTube users who document and share their experiences of using direct-to-consumer genetic testing kits for various diseases. The caregiver's account is akin to the "wayfaring" mode of weaving generational stories of users' past, present and future biologies (genetic predisposition to illness demonstrated by the kit read alongside the stories passed down in the family about pathological inheritance) in Harris' study but also differs from these in terms of "playfulness". While Harris' "consumers" engage playfully with their testing kits, performing the anticipation and excitement of "discovering" parts of their biological selves that have yet to or may never fully manifest, the caregivers studied here constantly underscore their awareness of the illness that permeates their daily lives through situations of filial care. Although they are in states of illness "liminality" in the sense that they oversee the care and management of illness in bodies other than their own in the family, their "autobiological" practices are nevertheless constantly governed by socio-cultural norms of filial duty and the institutional and professionalized prescriptions of medical care. A lapse in these norms is thus not viewed here as a form of "play" but often constitutes the potential for rights abuse, something I will return to in a later section.

I will now move on to exploring the discourse of rights articulated in the caregiver's account of illness experience in India. This discourse of rights also emerges as a detailing of the socio-cultural location of care and explores the intersection of civil rights and illness. The sociocultural location of care in these narratives can be organized under a) home and the institution of the family and b) narrative acts of empathetic interpretation. 


\section{Caregiving, Rights and "Home"}

"Home was where others had to gather grace. Home was what I wanted to flee". (Em and the Big Hoom, 147)

"Nothing was normal in our house". (Sepia Leaves, 206)

The narrators of Em and the Big Hoom and Sepia Leaves offer readers a very detailed view of the everyday routine of the home. Home in these texts is seen as the socio-cultural location where the primary burden of caregiving is borne. I will argue here that home is defined in the caregiver account of mental illness as the location of several kinds of rights abuse: narrators chronicle witnessing or experiencing sexual abuse, medical misdiagnosis and maltreatment, neglect and violence in their homes and at the hands of family ${ }^{\mathrm{ii}}$. Home is consequently visualized here as a source/location of pathology - the carer and cared for are seen to be always already embedded in a context that causes and often sustains mental illness. Pinto and Sandhu's narrators spend considerable time "thickening" the stories of those they care for (both novels are an account of mothers who are mentally ill and largely cared for at home) by offering readers stories of the patients' past. Imelda or Em in Pinto's novel and Manjeet Kaur or Mamman in Sepia Leaves are both seen to have arrived into their marriage as well as motherhood with much dislike and very little choice. Pinto records how Em always uttered the word "muddha" with contempt and rarely tried to censor her own account of how unwillingly she entered motherhood even to her children. In Sepia Leaves, Mamman and Baba never touch each other or even inhabit the same room and a symptom of Mamman's schizophrenia is that she suspects her husband is unfaithful and in a relationship with the woman who is taken in by the family to assist with chores and childcare. In the account of Mamman's past moreover, we learn that she is better qualified than her husband and was lied to about his professional status - she never comes to terms with living in circumstances that were vastly reduced from what she had imagined and during her manic episodes insists that she is not married and not to be referred to as "Mrs." Both narrators are thus marked as "sons" who were never meant to be recipients of care, possibly even before their birth. Their mothers' onset of depression and Schizophrenia is often traced back to a moment well before the inauguration of their own reciprocal, filial bonds (or duty) of care. For instance, Pinto's mother narrates to him her inexplicable crying at the thought of marrying his father (Pinto's father is seen to be a more than suitable partner by Imelda's mother, as a "brahmin" with a "good salary") and reads this as "crying for her childhood. My innocence, if you will" (128). Pinto's narrator then contextualizes this for the reader by situating his mother's marriage as only one in a long sequence of losses she experienced over her life:

Em had suffered migration, displacement and the loss of a home when she was still a girl. After arriving in India, she and her mother had spent some tough months in Calcutta before shifting to Bombay. There they had awaited the arrival of the man of the house, who was still walking from Burma to India through jungles and swamps, surviving malaria and tigers" (128)

Em's family's displacement from Burma during the Japanese invasion and her memories of this are even interpreted by Pinto early in the novel as the first sign of his mother's "breakdown", part of a "tribal way of expressing loss" (33). For Pinto, the family's exile to India, something that is recounted to him only via his mother and grandmother's stories, serves as one of the means of culturally locating his mother's illness.

Sepia Leaves similarly aligns the impact of political changes and the home when the narrator Appu as a child, first learns the meaning of the word "pagli" and what the declaration of a 
State of Emergency means at the same time. Indira Gandhi's declaration of a state of Emergency impacts everyday life in Rourkela where Sepia Leaves is set and in the small community of steel plant workers and their families where Appu lives, there is very little news that is not censored by State authorities. As a child, Appu recalls how little information he had control over receiving and understanding, especially about his mother's illness. His father for instance, struggles to explain the meaning of "Schizophrenia" to Appu, a term he encounters on his mother's prescription and the longest word he had heard until that time. In a similar fashion, he encounters the term "Pagli" when his neighbors describe his mother and is unable to understand the cultural import of the term. The Emergency for Appu is as opaque as the cultural and medical terms used to diagnose his mother. Trying to make sense of the curfews around him as well as his mother's illness, as his father explains Indira Gandhi's decision to cancel elections, he says:

'Like our home, where things are not normal? Like pagli?'

'No, not like our home. At home, there is no criminal. But yes, someone has gone mad in our country.'

'Who is that?'

'Well, many people. The police are mad. So is the army and so is Mrs. Gandhi. Yes, she is mad to do something like this,' Baba said, as he understood the comparison I was making.

'So Indira Gandhi is pagli too,' I concluded. "If she is not normal then she is pagli....' (918919)

Appu's interpretation of the curfews as "madness" and his alignment of this with the home displaces the distinction between inside and outside - home as a space of safety, unaffected by a very volatile political situation outside. As a child, he pathologises the declaration of the Emergency while simultaneously taking comfort in finding a coherent and familiar framework through which to explain his mother's condition and its impact on their home.

The caregiver account here thus situates the heteronormative family unit and cultural/communal experiences of loss, displacement and fear as bearing the potential for and being equivalent to the illnesses of those that require their care. In addition, the caregiver account also details the abuse of rights that takes place in the home, thus interrogating the safety and "humane" nature of the home when compared to institutional contexts of care. Appu in Sepia Leaves for instance, details how his aunt was largely responsible for his mother's treatment and diagnosis and sees her write his mother's prescriptions without ever having a conversation with her. Appu also witnesses his mother's physical abuse by his uncles at his father's home - a reaction to something she says during a manic episode. Appu is himself the victim of abuse at the hands of his mother, especially when she imagines herself to be Kali, a goddess of destruction and him to be the demon that she is to vanquish. Pinto similarly describes being at the receiving end of plenty of verbal abuse from Em whose words could then also be easily ignored as a "symptom". She is no longer rendered a person when her words are dismissed as being a consequence of her illness. The burden of caring for Em is also very palpable for the family because of her multiple suicide attempts. Unable to afford a nurse, the family often leaves Em alone at home, paradoxically relying on "her word" that she will not attempt to take her own life. Pinto's narrator testifies to the horrors of the psychiatric wards in Mumbai hospitals but still "sends" Em to one of these when his father is away on work. The burden of caregiving here overrides concern for Em's "humane" treatment and when she returns from the hospital having undergone several rounds of Electro convulsive therapy, Pinto records how she looks as though she was "returned from the 
dry-cleaners"' (204). The caregiver account thus demonstrates the various modes through which contexts of care can themselves become a potential location for rights abuse.

The caregiver's detailing of at-home care necessitated by illness designates the space of the home as a kind of heterotopia, a place which in Foucault's terms is a "counter-site" that represents, inverts and contests all the other "real sites" that are found in a culture (24). For instance, in the caregiver account, the home interrupted by illness is transformed into a pseudoclinical setting governed by the medical management of the ailing subject. Moreover, this place of care is sustained and mandated by filial relationships and duties rather than the institutional and professional code of the hospital. The caregiver narrates from this location to question the laws/modes of operation that govern the space of the home when it is interrupted by illness professional standards of "treatment" are expected in a space that is not governed entirely via the traditional agents of medical care. In such a situation, the caregiver's account of witnessing rights abuses in the context of at-home care of illness questions the "normative" contexts in which the "ailing subject" is defined as "human". The caregiver poses questions about the "normativity" of the subject in the context of illness and through the "thickening" of socio-cultural contexts in which this subject is embedded, also signals at the non-place occupied by those who are neglected within medical practices carried out outside traditional places of treatment. The home as a threatening and volatile space for the carer and the cared for is countered in the caregiver's account through acts of "empathetic interpretation" which I will detail in the next section.

\section{The Right to "speak" and be "heard": Empathetic interpretation in the Caregiver account}

In addition to "thickening" the patient's story for the reader by offering a detailed cultural and social context for the ailing individual and the ailment itself, the caregiver account is also characterized by a portrait of the cared for as an "individual". By "individual", I mean a narrative portrait that reasserts personhood primarily through demonstrating the relational nature of caregiving relationships. Illness in the caregiver account, is only an occasion for narrating a family history and is eventually subsumed by this history. The caregiver translates the "ailing subject" or "schizophrenic" as seen in medical terms into personhood by building a family history not necessarily to explain or locate the "source" of illness. This contrasts with the medical case history whose organizing principle is always the illness, where family narratives are translated by the physician or relevant only so far as they are causal factors. As argued earlier, locating pathology as always already present in the home is one mode through which "illness" is seen not only as an "individual's" burden or responsibility. In another sense, the caregiver account demands equivalences between losses and suffering of various kinds that remain "undiagnosed" or pronounced as moments requiring care and the suffering of mental illness which continues to be poorly understood and dealt with largely within the family in India. Personhood is reasserted for the caregiver and the patient by demonstrating how they are not solely connected via illness and its medical management alone. For instance, Pinto's novel details the process through which he uncovers the story of his parents' lives before they were married. Pinto's narrator is presented as an assiduous researcher - he parses the letters his parents wrote to one another and reproduces several of these for the reader. He often pits several family members' versions of the same event against one another and thus presents the reader with the processes through which he attempted to arrive at the truth of any situation/circumstance. Sandhu similarly describes how Antaryamin, the newspaper delivery boy and Mando, his helper at home, are Appu's sources of information in regard to any news that is censored before it reaches him. When Mando is sexually abused during

a robbery at home when Appu and his parents are away, it is Antaryamin who describes the 
episode to Appu even though his father was the one questioned by the police after the incident. Moreover, the steel plant workers' community and their perception of Appu's family is also something that he is seen to discern entirely through his persistent questioning of Mando, Antaryamin and his father. The caregiver is thus seen to work hard for the story he must piece together and explicitly demonstrates his reliance on the stories of others. More significantly, the caregiver demands equivalences between several kinds of traumatic events and experiences and illness managed at-home, thereby reasserting this space as a context in which rights ought to be renegotiated.

Appu in Sepia Leaves starts paying attention to his mother's stories and observes how "when she spoke freely and at length, she was calm for a few hours" (2139 - 2140). Although he details his fear of being physically assaulted by his mother when she imagined herself to be Kali, he also records how even the curfews imposed during the Emergency could not stop his mother and when he sees the film Hunterwali for the first time he says that Nadia's (the well-known stunt performer/actress of the time) stunts reminded him of his mother hitting his father. Appu attempts an empathetic identification with his mother who he sees as being "misunderstood" rather than ailing. He draws equivalences between her speaking to herself and his own practice of speaking to "his inner ear" when he becomes increasing isolated and lonely as an older boy at boarding school. He thus views his mother's symptoms as a result of a particular circumstance rather than as the upside-down logic of an illness that "interrupts" an otherwise normal life. His "inner ear" through which he identifies with his mother is also a source of comfort rather than a symptom that causes worry as a potential genetic link to his mother's illness. Pinto's narrator similarly marvels at the felicity with which Em always listens and responds to strangers she meets at the hospital, sometimes immediately following an episode of mania at home which was always characterized by rage and abuse directed at family members. More significantly, Pinto preserves his mother's words about how she perceives her illness - she describes it as a "tap" that opened sometime when he was born which initiated a "black drip" that continued to this day. Pinto refuses to commit in the novel to any diagnostic label for his mother's illness but the novel itself progresses in large part through conversations with his mother. Pinto's narrator's conversations are in reported speech to preserve the circularity, freely-associative and cultural-linguistic register in which Em speaks. About his experience of these conversations he says,

I tried to believe Em in everything she said. It was my act of faith, because I could see how the outside world immediately discounted whatever she said. But I wanted so hard to believe that I often found myself in the position of the inquisitor, the interrogator, demanding verification, corroboration, further proof. Most of the time, she didn't seem to mind. (27)

Pinto is thus demonstrating here, the importance of an autonomous linguistic register for the patient in which to be heard, understood and interpreted without recourse to a "diagnosis" that renders all speech after this point only fit to be "discounted". He is also demonstrating the labour of care as not being exclusive to the event of illness but rather one that can extend to any situation where we hear another's account of an event that impacted their lives. Caring here is wanting "so hard to believe" and performing the labour of "inquisition, interrogation, verification and corroboration". Caregiving as an "interpretative act" is thus demonstrated here as parsing the words for others for shared modes of meaning and understanding. This "interpretative act" can be seen as an attempt to overturn "listening" and "hearing" from being merely processes of reception to those that are also modes of production as Ratcliffe has argued (1999). Inviting us to consider rhetorical "listening" on par with writing, reading and speaking, Ratcliffe asserts that when we 
read in order to locate the "exiled excess" in a text and reflect on how this relates to ourselves and our culture, we move beyond empathy alone. Instead, we are able to acknowledge that something that cannot be seen can still be "heard" in the text thus creating a more "inclusive logos" which has a potential for greater personal and social justice (203). The caregiver's interpretative act demonstrates this "rhetorical listening" where he instantiates our ethical responsibility as readers/listeners of the ailing subject's narrative while simultaneously questioning what is considered "fair" and "just" in situations of care.

This paper has demonstrated that the caregiver's account produces a rights discourse that seeks to restore personhood to those in the care situation brought on by illness and its medical management. The caregiver accounts studied here seek to establish social and cultural contexts of illness to underscore individual circumstances of illness. At the same time, these individual circumstances are seen to belong to a group and are unified in their location in the space of the home, within the institution of the family. The rights of individuals in a care situation/relationship are thus located in a collective and are seen to have local as well and regional/national importance. The caregiver account seeks to redress the loss of personhood in the context of illness and medical treatment through interpretative acts that locate ailing individuals and their carers in reciprocal relationships where the story/perspective of the first does not find meaning without the interpretative acts of the second.

\section{Notes}

\footnotetext{
${ }^{\mathrm{i}}$ These narratives include first-person accounts of treating and experiencing illness. Some of the important sub-genres in illness narratives include physician and patient memoirs. See Donald Pollock's "Physician Autobiography: Narrative and the Social History of Medicine" (for a study of how novice (trainee) physicians use the memoir form for raising questions about rights violations in medical practice and training. See Michael Bury's "Chronic Illness as Biographical Disruption" (2001) for a discussion of how illness affects our capacity to make sense (or a story) of our self. See Arthur Frank's works (1993) and (2007) for a much-cited discussion of the various forms and modes through which we organize "stories" of illness.

${ }^{\text {ii }}$ See Nayar (2009) for a discussion of narratives by the homeless mentally ill where the idea of a safe home and secure family are challenged and illness is purportedly "engineered" at home or exacerbated through abandonment by families.
}

\section{References}

Burack-Weiss, Ann. (2006). The caregiver's tale: Loss and renewal in memoirs of family life. New York: Columbia University Press.

Bury, Michael. (1982). Chronic illness as biographical disruption. Sociology of Health and Illness, 4 (2), 167182.

Dawes, James. (2009). Human Rights in Literary Studies. Human Rights Quarterly, 31 (2), 394-409.

Foucault, M., \& Miskowiec, J. (1986). Of Other Spaces. Diacritics, 16 (1), 22-27.

Frank, A. W. (1993). The rhetoric of self-change: Illness experience as narrative author. The Sociological Quarterly, 34 (1), 39 - 52. 
Harris, A, Kelly, S. E. \& Wyatt, S. (2014). Autobiologies on YouTube : Narratives of direct-to-consumer genetic testing. New Genetics and Society, 33 (1), 6o - 78.

Nayar, P. K. (2016). Human Rights and Literature: Writing Rights. New York: Palgrave.

Nayar, P. K. (2011). Subalternity and Translation: The Cultural Apparatus. Economic and Political Weekly, 46 (9), 23-26.

Nayar, P. K. (2009). Postcolonial affects: Victim life narratives and Human Rights in contemporary India. Postcolonial Text 5 (4), 1-22.

Pinto, Jerry. (2012). Em and the Big Hoom. New Delhi: Aleph.

Pollock, Donald. (200o). Physician autobiography. In Mattingly, Cheryl \& Garro, Linda (Eds.), Narrative and the Cultural Construction of Illness and Healing (108-127). Berkeley: University of California Press.

Ratcliffe, K. Rhetorical listening (1999): A trope of interpretive invention and a code of cross-cultural conduct. College Composition and Communication, 51 (2), 195-224.

Rowe, Michael. (2002). Metamorphosis: Defending the human. Literature and Medicine, 21 (2), 264-28o.

Sandhu, Amandeep. (2008). Sepia Leaves [Kindle edition]. Retrieved from Amazon.in

Schaffer, Kay \& Smith, Sidonie. (2004) Human Rights and narrated lives: The ethics of recognition. New York: Palgrave.

Slaughter, J. R., \& McClennen, S. A. (2009) Introducing Human Rights and literary forms; or, the vehicles and vocabularies of Human Rights. Comparative Literature Studies, 46 (1), 1-19.

Whitehead, Anne. (2011). Writing with care: Kazuo Ishiguro's Never Let Me Go. Contemporary Literature, 52 (1), 54-83. 